\title{
Article \\ Hydrological Effects of Prefabricated Permeable Pavements on Parking Lots
}

\author{
Kechang Dai ${ }^{1,2}$, Weixing Liu ${ }^{1,2, *, \dagger}$, Xiaotian Shui ${ }^{1,2,+}$, Dafang Fu ${ }^{1,2,3,+}$, Chris Zevenbergen ${ }^{4}$ \\ and Rajendra Prasad Singh $1,2,3, *,+(\mathbb{D}$ \\ 1 School of Civil Engineering, Southeast University, Nanjing 211189, China; 220191092@seu.edu.cn (K.D.); \\ 220194427@seu.edu.cn (X.S.); fdf@seu.edu.cn (D.F.) \\ 2 Jiangsu Sponge City Material and Performance Testing Engineering and Technology Research Center, \\ Kunshan 215300, China \\ 3 Monash University Joint Research Center for Future Cities, Southeast University, Suzhou 215123, China \\ 4 IHE-Delft, Institute of Water Education, 2601 DA Delft, The Netherlands; c.zevenbergen@un-ihe.org \\ * Correspondence: liuweixingstyle@163.com (W.L.); rajupsc@seu.edu.cn (R.P.S.) \\ + Co-first authors-have equal contribution.
}

check for updates

Citation: Dai, K.; Liu, W.; Shui, X.; Fu, D.; Zevenbergen, C.; Singh, R.P. Hydrological Effects of Prefabricated Permeable Pavements on Parking Lots. Water 2022, 14, 45. https:// doi.org/10.3390/w14010045

Academic Editors: Amit Kumar and Zhiguo Yu

Received: 31 October 2021

Accepted: 9 December 2021

Published: 24 December 2021

Publisher's Note: MDPI stays neutral with regard to jurisdictional claims in published maps and institutional affiliations.

Copyright: (C) 2021 by the authors. Licensee MDPI, Basel, Switzerland. This article is an open access article distributed under the terms and conditions of the Creative Commons Attribution (CC BY) license (https:// creativecommons.org/licenses/by/ $4.0 /)$.

\begin{abstract}
Permeable pavements can infiltrate and reduce stormwater runoff in parking lots, but issues around long construction periods and proper maintenance still required proper research and further understanding. The application of precast concrete can help to solve this. In this study, precast concrete components were applied to the design of permeable pavements to form prefabricated permeable pavements. The laboratory study is one of the first to examine the hydrological effect of prefabricated pervious pavements in parking lots. Four kinds of permeable pavements were designed and manufactured. These had different materials (natural sand-gravel, medium sand) which comprised the leveling layer or different assembly forms of precast concrete at the base. Three scenarios of rainfall intensity $(0.5,1$, and $2 \mathrm{~mm} / \mathrm{min})$ and three rainfall intervals (one, three, and seven days) were simulated using rainfall simulators. The initial runoff time, runoff coefficient, and runoff control rate of each permeable pavement were investigated during the process of simulating. Results showed that the initial runoff time was no earlier than $42 \mathrm{~min}$, the maximum runoff coefficient was 0.52 , and the minimum runoff control rate was $47.7 \%$ within the rainfall intensity of $2 \mathrm{~mm} / \mathrm{min}$. The initial runoff time of each permeable pavement was no earlier than $36 \mathrm{~min}$ when the rainfall interval was one day, whereas, the maximum runoff coefficient was 0.64 , and the average runoff control rate was $41.5 \%$. The leveling layer material had a greater impact on the hydrological effect of permeable pavements, while the assembly form of precast concrete had no significant effect. Compared with natural sand-gravel, when the leveling layer was medium sand, the runoff generation was advanced by 4.5-7.8 min under different rainfall intensities, and 7-10 min under different rainfall intervals. The maximum runoff coefficient increased with about $14.6 \%$ when the rainfall interval was one day. Among four kinds of permeable pavements, the type I permeable pavement had the best runoff regulation performance. The results revealed that all prefabricated permeable pavements used in this study had good runoff control performance, and this design idea proved to be an alternative for the future design of permeable pavements.
\end{abstract}

Keywords: permeable pavement; parking lot; sponge city; runoff; rainfall intensity

\section{Introduction}

Large-scale economic activities and rapid urbanization in recent years have created numerous environmental and developmental challenges. Due to enormous pressure on urban areas, cities are exposed to frequent flooding. For example, in China and other developing countries, a large number of cities are facing frequent flooding problems, resulting in huge social, economic, and environmental impacts [1,2]. Climate change is evident in the urban environment and increases in the global ambient temperature will 
cause severe flooding and depletion in water quality in major water resources in many developed and developing countries [3,4]. As waterlogging is considered as one of the major underlying causes of these impacts, the management of urban drainage is a big challenge for both researchers and government authorities [5,6]. Flooding is also one of the most common and destructive natural perils causing huge economic and human loss annually worldwide [7]. Continuous increases in the number of light vehicles e.g., cars in urban areas make it essential to find suitable locations for the construction of parking lots and permeable pavements. Due to the lack of proper research and guidelines for the construction and management of permeable pavements in parking lots and the selection of suitable sites, it is highly significant to evaluate the current situation of urban development and conduct proper research on permeable pavements [4-8].

Permeable pavements are regarded as one of the effective tools for controlling urban surface runoff and peak flow reduction, due to their high infiltration rate [3,7-12]. Hard pavement increases the impervious area in cities, causing problems, such as increased waterlogging risk, reduced groundwater recharge, and deterioration of the water environment $[13,14]$. Due to the rapid development of sponge city construction in China, permeable pavements are widely used in parking lots and roads with small loads $[15,16]$, and play a crucial role in rainfall runoff reduction and retention [17]. Cheng et al. [18] installed two types of pavements (a porous asphalt bicycle lane and a permeable interlocking concrete brick) in Taipei City and found good stormwater runoff control performance, such as peak runoff and volume reduction. Their study also suggested that large-scale applications of porous pavements could help to mitigate urban heat island impacts. Park et al. [19] analyzed infiltrate characteristics of permeable concrete and permeable block pavement in a parking lot at full scale. Three scenarios of rainfall intensity were simulated and the results showed that permeable pavements delay the initial runoff time and reduce the peak flow. The total runoff was also reduced, which was shown by the runoff reduction ratio of each pavement. Ghisi et al. [20] used permeable interlocking concrete pavements to filter stormwater and assessed the possibility of the filtered water for non-potable uses in buildings. The quantity and quality of the filtered water were tested. The results showed that the use of permeable interlocking concrete pavement can be used for the pretreatment of non-potable water in buildings.

However, permeable pavement has many disadvantages, such as a long construction period, easy clogging, and difficult maintenance work, and these factors limit its applications [21]. Precast pervious concrete panels manufactured with open-graded aggregate is considered as an emerging, innovative product which has potentials to help solve these problems. This first project of the application of this product in parking lots have been reported [22].

At present, prefabricated permeable pavement can be divided into three categories: the first type is prefabricated on the surface layer (the surface layer is mainly constructed of permeable prefabricated concrete that interlocks with each other); the leveling layer (which consists of sand and gravel, etc.); and the base layer (which mainly consists of graded gravel and geotechnical materials) [18-24]. Walter et al. [25] designed interlocking permeable prefabricated concrete and pavement, which had the advantages of low maintenance, high quality, and cost-effectiveness, among others. The second type is prefabricated on the base [24-26]. The base is made of permeable prefabricated concrete that is interlocked with each other. The leveling layer is made of the same materials as the previous one, and the surface layer is made of permeable brick, permeable asphalt, and permeable concrete, etc. Yang et al. [27] have designed a prefabricated permeable sidewalk base block. The application results showed that the pavement had good permeable and water-retaining performance and strong compressive capacity. The third type adopts integral prefabrication, integral casting and forming, without distinguishing structural layers. Bateni et al. [28] developed a permeable pavement structure with micro-scale flood detention capacity. The main body was a hollow cylinder with hexagonal blocks on the top and the bottom. The simulated rainfall test showed that its hydrological effects met the requirements of a typical 
permeable pavement. When the rainfall return period is 1:100 years, the peak rainfall can be delayed by $15 \mathrm{~min}$.

The existing literature reveals a lack of proper understanding regarding the use of prefabricated permeable pavement in parking lots and its impact of the hydrology. The aim of this study is to assess the runoff control performance of four types of permeable pavements under different rainfall intensities and different rainfall intervals. Laboratory experiments have been conducted to simulate conditions of areas which are prone to frequent flooding and waterlogging. In addition, the relative impact of the different composition materials in the leveling layer and different assembling forms of precast concrete at the base on their hydrological effect were also investigated to determine the optimal design.

\section{Materials and Methods}

\subsection{Structure of Fabricated Permeable Pavement}

Current work focused on analyzing hydrological effects of prefabricated permeable pavements was conducted at the Jiangsu Sponge City Material and Performance Testing Engineering and Technology Research Center, Kunshan, Jiangsu province, China.

Figure 1 shows the structural model of permeable pavements used in this study.

Surface layer: Permeable clay brick with a thickness of $55 \mathrm{~mm}$;

Leveling layer: Natural sand-gravel or medium sand with a thickness of $100 \mathrm{~mm}$. A layer of permeable geotextile was paved at the bottom;

Base layer: Permeable precast concrete components, which were divided into two types $(a, b)$ according to different assembly forms. The schematic designs and the assembling structure of the precast concrete are shown in Figure 2. The type-a assembly was formed by splicing two L-shaped members up and down. The b-shaped piece included two Lshaped components and one "convex" shaped irregular component. Compared with type-a, the type-b assembled form had a tighter interlocking structure and a stronger carrying capacity. The strength grade of concrete was C20. The cementitious system contains both natural aggregate and recycled aggregate, and their ratio was 1:1. Aggregate gradation: $4.75-9.5 \mathrm{~mm}$ particle size accounted for $20 \%, 9.5-19 \mathrm{~mm}$ particle size accounted for $50 \%$, and $19-31.5 \mathrm{~mm}$ particle size accounted for $30 \%$. The aggregate-cement ratio was 3.5 , and the water-cement ratio was 0.3 . According to the results of our previous experiments, the compressive strength (28 day compressive strength was $11.53 \mathrm{Mpa}$ ) and porosity $(21.3 \%)$ of the precast concrete were comprehensively optimal under this gradation. Subbase: natural graded gravel with a thickness of $50 \mathrm{~mm}$. Impervious geotextile and geogrid were utilized at the bottom to prevent contamination in groundwater.

Four different types of prefabricated permeable pavements were made by using different materials for the leveling layer and assembly forms of the precast concrete components. Table 1 describes the individual designs.

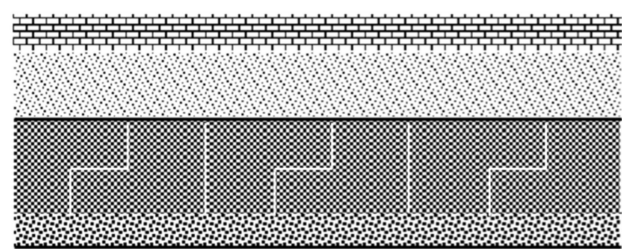

(a)

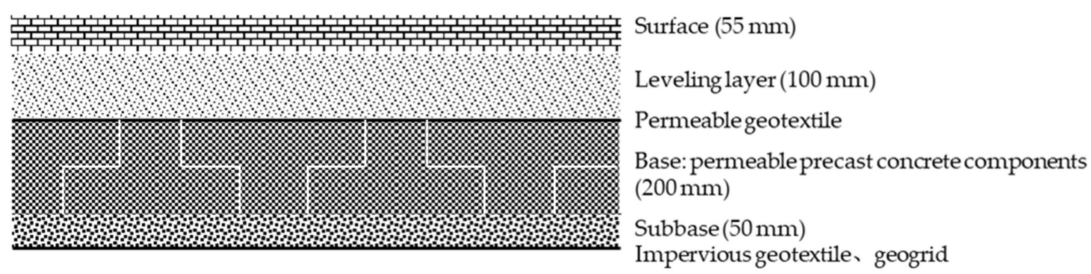

(b)

Figure 1. Permeable pavement model used in the study: (a) precast concrete in type a; and (b) precast concrete in type b. 


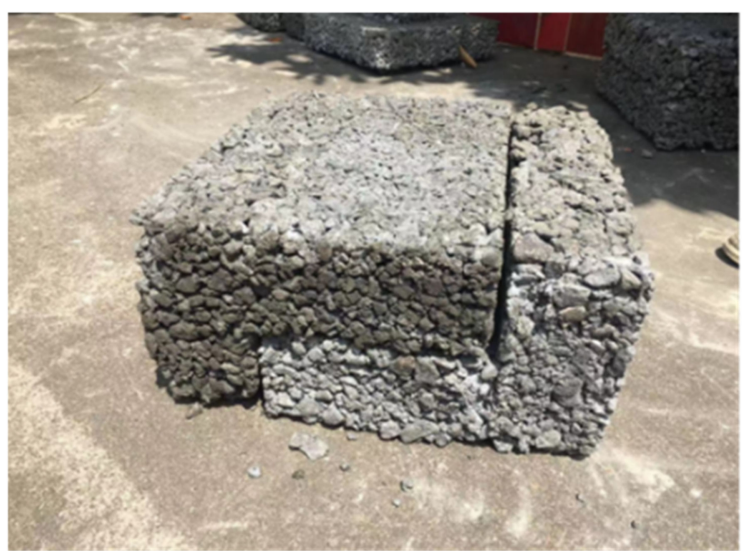

(a)

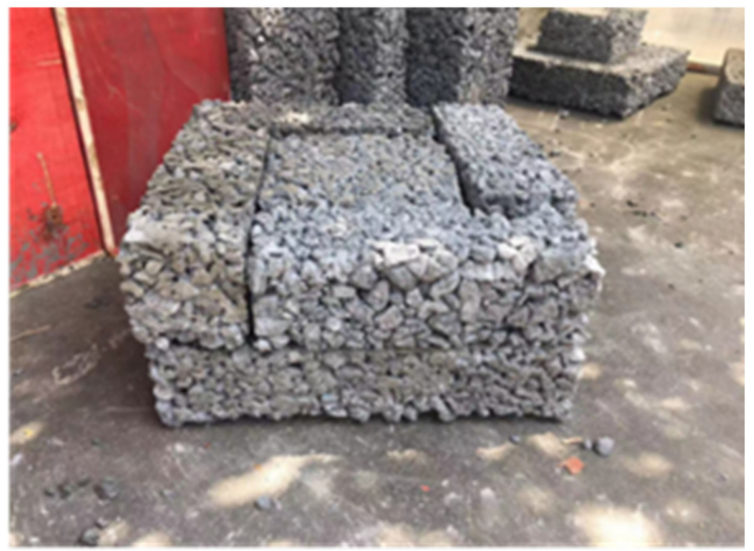

(b)

Figure 2. Precast concrete components: (a) type a; and (b) type b.

Table 1. Design of four types of prefabricated permeable pavements.

\begin{tabular}{ccccc}
\hline Type & Surface & Leveling Layer & Base & Subbase \\
\hline I & & Natural sand-gravel & Type a & \\
II & Water permeable & Type b & Natural graded \\
III & brick & Medium sand & $\begin{array}{c}\text { Type a } \\
\text { Type b }\end{array}$ & \\
IV & & & crushed stone \\
\hline
\end{tabular}

\subsection{Experimental Set-Up}

The experimental device used in the current study (as shown in Figure 3) mainly consists of four parts: water supply facilities, flow regulation facilities, permeable pavement facilities, and rainfall-runoff collection facilities. The permeable pavement structure is placed in an iron cuboid box, which is $0.4 \mathrm{~m}$ long, $0.4 \mathrm{~m}$ wide and $0.5 \mathrm{~m}$ high. Every permeable pavement is $0.4 \mathrm{~m}$ long, $0.4 \mathrm{~m}$ wide and $0.45 \mathrm{~m}$ high. Tap water for simulating rainfall is stored in the water tank. The opening of the valve is adjusted according to the reading of the flowmeter to make the rainfall intensity meet the set value. The runoff generated from the surface overflowed through the overflow hole on one side of the device, and then it is collected and measured. The infiltrated rainwater is discharged through the drainage hole at the bottom of the device and is also collected and measured.

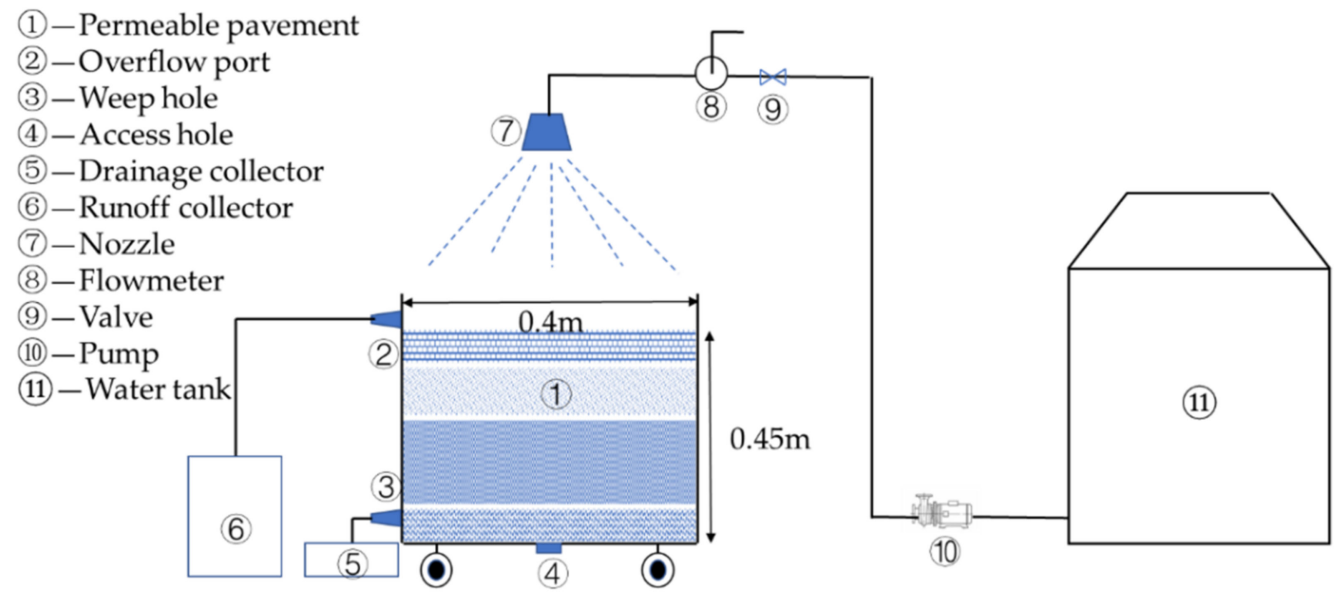

Figure 3. Schematic diagram of the experimental device. 


\subsection{Experimental Scheme}

The indicators reflecting the hydrological performance of permeable pavements in this study include initial runoff time, runoff coefficient, and runoff control rate.

Experiment 1 was conducted to investigate the hydrological performance of each permeable pavement under different rainfall intensities. The three rainfall intensities included $0.5 \mathrm{~mm} / \mathrm{min}, 1 \mathrm{~mm} / \mathrm{min}$, and $2 \mathrm{~mm} / \mathrm{min}$; all these are considered to be above moderate rain. At every rainfall intensity, the rainfall interval was seven days and the rainfall duration was $2 \mathrm{~h}$.

Experiment 2 was conducted to investigate the hydrological performance of each permeable pavement under different rainfall intervals. The rainfall intervals included 1 day, 3 days, and 7 days. At every rainfall interval, the rainfall intensity was $2 \mathrm{~mm} / \mathrm{min}$ and the rainfall duration was $2 \mathrm{~h}$.

\subsection{Experimental Procedure}

The experimental work was performed in the following steps:

1. Enough tap water was stored in the bucket to guarantee at least one experiment.

2. The pump was opened and the opening of the valve was adjusted according to the reading of the flowmeter to ensure that the rainfall intensity reached the set value.

3. The surface of the permeable pavement structure was observed, and the time was recorded by a stopwatch when overflow occurred.

4. After the rain, the pump and valve were closed, and the amount of rainwater overflow was measured.

5. The drainage outlet at the bottom of the device was kept open and the rainwater accumulated in the permeable pavement was approximately emptied.

6. The mobile water tank pump was stopped for the rainfall interval before the next experiments.

\subsection{Data Processing and Analysis}

Initial runoff time: The surface of the permeable pavement was observed, and the time was counted with a stopwatch. When the rainwater began to overflow, the time was recorded. This time was taken as the initial runoff generation time of permeable pavements.

Runoff coefficient: The runoff generation amount was recorded every $10 \mathrm{~min}$. The runoff coefficient was calculated according to Equation (1).

$$
\varphi=\frac{Q}{1000 i A}
$$

where: $\varphi$ is the runoff coefficient; $Q$ is the runoff generation, $\mathrm{m}^{3} / \mathrm{h} ; i$ is the rainfall intensity, $\mathrm{mm} / \mathrm{h}$; and $A$ is the confluence area, $\mathrm{m}^{2}$.

Runoff control rate: After rainfall, the amount of rainwater in the runoff collector was measured. This amount was divided by the surface area of the permeable pavement to obtain the runoff generation amount, and the unit was $\mathrm{mm}$. The total rainfall was obtained by multiplying rainfall intensity and rainfall duration, and the unit was $\mathrm{mm}$. Cumulative infiltration was the difference between the total rainfall and the runoff generation amount. The runoff control rate was obtained by dividing the infiltration amount by the total rainfall.

Results were statistically analyzed using the analysis of variance (ANOVA) testing method and graphs were prepared by using Origin8.1 software.

\section{Results and Discussion}

\subsection{Hydrological Effect of Permeable Pavement under Different Rainfall Intensities}

\subsubsection{Initial Runoff Time}

Results for the initial runoff time for each prefabricated permeable pavement under different rainfall intensities are presented in Table 2. The results revealed that when the rainfall intensity is $0.5 \mathrm{~mm} / \mathrm{min}$, all permeable pavements did not produce runoff. At this 
time, the rainfall intensity was less than the infiltration capacity of the permeable pavement. When the rainfall intensity increased, each permeable pavement produced runoff. The greater the rainfall intensity, the earlier the runoff time would be. Within the rainfall intensity of $2 \mathrm{~mm} / \mathrm{min}$, the initial runoff time of each permeable pavement was later than $42 \mathrm{~min}$, which indicated that the permeable pavement had a strong flood staggering ability.

Under similar rainfall intensity conditions, the initial runoff time of type III and type IV permeable pavement was earlier than that of type I and type II by $4-7$ min, and the difference increased with the increase of rainfall intensity. It showed that the leveling layer material had a great influence on the initial runoff time. The gravel layer delayed runoff generation, which was consistent with the findings of Liu et al. [29]. Their findings reveal delayed runoff generation with increased thickness in the gravel layers. When the leveling layer was medium sand, the permeable pavement produced runoff earlier. This trend occurred because, compared with natural sand and gravel, medium sand had a smaller porosity and lower infiltration capacity, and rainfall could not easily pass through this layer, which was consistent with previous findings [30]. The results revealed that when the leveling layer material of the permeable pavement was the same, the initial runoff time was similar. In case where the base form was type $b$, the runoff time was advanced by 1-2 min. This was due to the interlocking structure of the type-b assembly which was more complicated, and the water flow path was tortuous, which caused the flow rate to slow down and start earlier. Due to the minor difference, it showed that under different rainfall intensities, the structure form of the base had little effect on the initial runoff time.

Table 2. Initial runoff time of each permeable pavement under different rainfall intensities.

\begin{tabular}{ccccc}
\hline \multirow{2}{*}{$\begin{array}{c}\text { Rainfall Intensity } \\
\text { (mm/min) }\end{array}$} & Type I & Type II & Type III & Type IV \\
\cline { 2 - 5 } & 0 & 0 & 0 & 0 \\
0.5 & 58 & 58 & 54 & 53 \\
1 & 51 & 49 & 43 & 42 \\
\hline
\end{tabular}

\subsubsection{Runoff Coefficient}

The runoff coefficient of each permeable pavement under different rainfall intensities is shown in Figure 4. When the rainfall intensity was $0.5 \mathrm{~mm} / \mathrm{min}$, each permeable pavement would not produce runoff within $2 \mathrm{~h}$, so the runoff coefficient was 0 , which is not presented in Figure 4. With the increase of rainfall intensity, the runoff coefficient of each permeable pavement increased significantly. At the end of the rainfall (90-120 min), the runoff coefficient of each permeable pavement at $2 \mathrm{~mm} / \mathrm{min}$ was about 1.9-2 times that at $1 \mathrm{~mm} / \mathrm{min}$.

Under the same rainfall intensity, the runoff coefficient of permeable pavement increased with time. This was because the rainfall intensity remained constant during the simulated rainfall process, and the structural layers of permeable pavement were gradually filled with water. The infiltration rate slowed down, and thus the runoff increased continuously. When the material of the leveling layer was the same, the runoff coefficient of the permeable pavement was similar (difference was within 0.01), indicating that the structural form of the base had no effect on the runoff coefficient. In cases when the base structure was the same, the runoff coefficient of the permeable pavement was similar (within 0.05), indicating that the material of the leveling layer had little effect on the runoff coefficient. Similar results were noted in the previous studies for permeable pavements installed in parking lots [3,20-23]. 


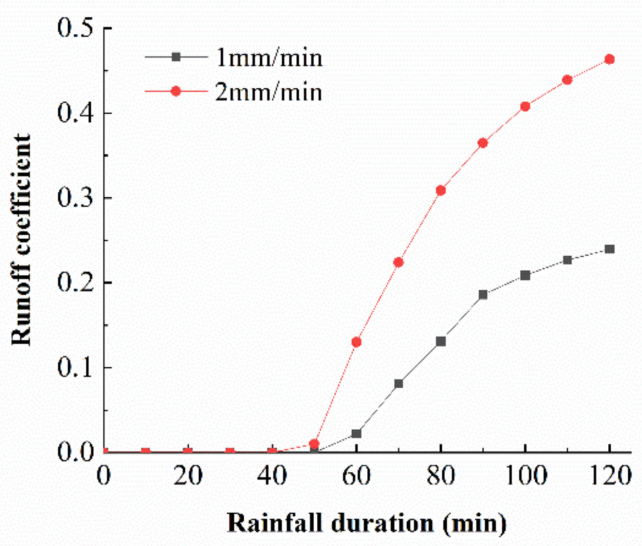

(a)

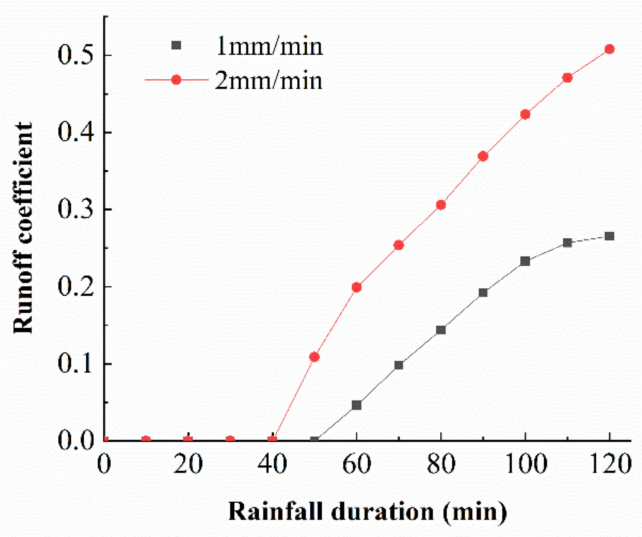

(c)

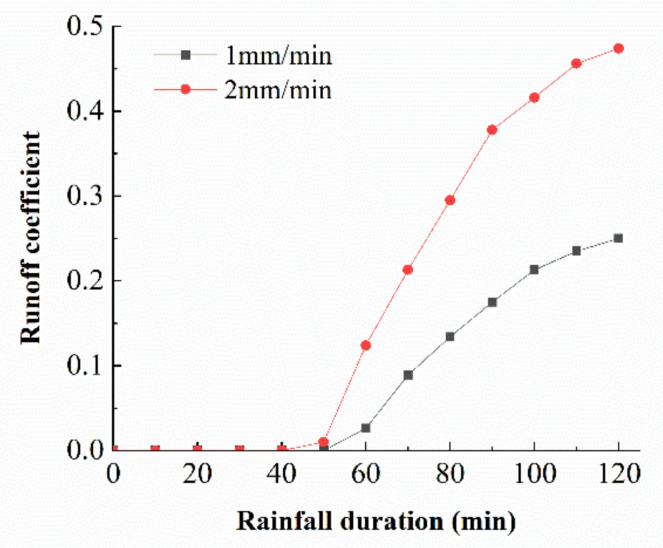

(b)

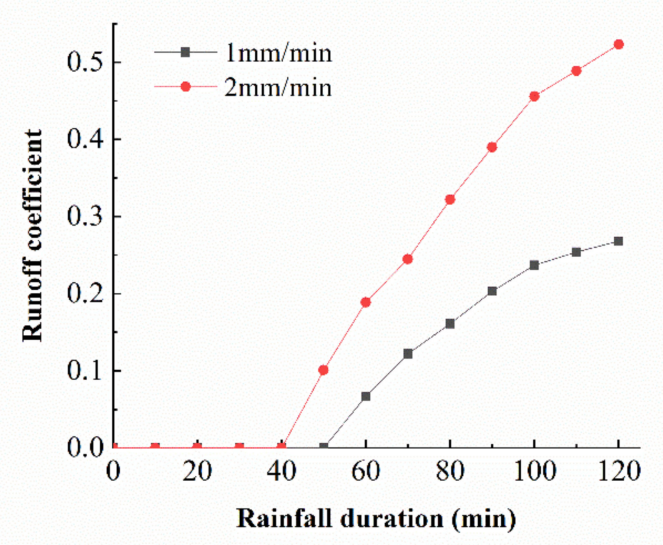

(d)

Figure 4. Runoff coefficient of each permeable pavement under different rainfall intensities: (a) type I; (b) type II; (c) type III; and (d) type IV.

\subsubsection{Runoff Control Rate}

The runoff generation and cumulative infiltration amount of each permeable pavement under different rainfall intensities are shown in Figure 5, and the runoff control rate is shown in Table 3. When the rainfall intensity was $0.5 \mathrm{~mm} / \mathrm{min}$, the runoff control rate was $100 \%$. With the increase of rainfall intensity, the runoff generation increased, and the runoff control rate decreased. When rainfall intensity was $1 \mathrm{~mm} / \mathrm{min}$ and $2 \mathrm{~mm} / \mathrm{min}$, the runoff control rate was $73.2-76.0 \%$ and $47.7-53.6 \%$, respectively.

The results revealed that when the structure form of the base was the same, and the runoff control rate: type I > type III, type II > type IV, at $2 \mathrm{~mm} / \mathrm{min}$, the difference was $4.4 \%$ and $4.9 \%$, respectively. This showed that compared with medium sand, natural sand and gravel was more conducive to runoff reduction. This may be due to the lower porosity and stronger water holding capacity after water absorption of medium sand compared with natural sand and gravel $[5,8,20]$. In cases when the material of the leveling layer was the same, the runoff control rate of the permeable pavement was similar (within 1.5\%), which indicated that the base form had minor effect on the runoff control rate. 


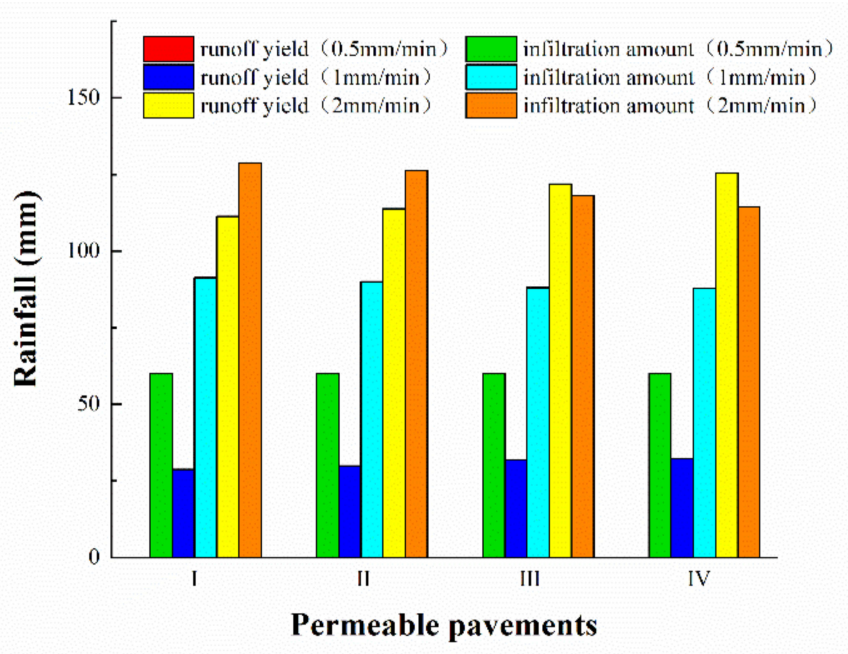

Figure 5. Yield and infiltration of each permeable pavement under different rainfall intensities.

Table 3. Runoff control rate of each permeable pavement under different rainfall intensities.

\begin{tabular}{ccccc}
\hline \multirow{2}{*}{$\begin{array}{c}\text { Rainfall Intensity } \\
(\mathbf{m m} / \mathbf{m i n})\end{array}$} & Type I & Type II & Type III & Type IV \\
\cline { 2 - 5 } & 100 & 100 & 100 & 100 \\
0.5 & 76.0 & 75.0 & 73.4 & 73.2 \\
1 & 53.6 & 52.6 & 49.2 & 47.7 \\
\hline
\end{tabular}

\subsection{Hydrological Effects under Different Rainfall Intervals}

\subsubsection{Initial Runoff Time}

The initial runoff time of each prefabricated permeable pavement under different rainfall intervals is shown in Table 4. The smaller the rainfall interval, the sooner the permeable pavement would produce runoff. When the rainfall interval was 1 day, there was no runoff before $36 \mathrm{~min}$ of all permeable pavements. The latest time for the permeable pavement to generate runoff was $51 \mathrm{~min}$, which occurred in type I permeable pavement, and the rainfall interval was seven days. When the rainfall interval was three days and seven days, the initial runoff time of each permeable pavement was similar, which showed that when the rainfall interval was longer than three days, and the initial runoff time was basically stable. This trend is consistent with previous findings in which researchers found similar results $[4,12,20,26]$.

Table 4. Initial runoff time of each permeable pavement under different rainfall intervals.

\begin{tabular}{ccccc}
\hline \multirow{2}{*}{$\begin{array}{c}\text { Rainfall Interval } \\
\text { (d) }\end{array}$} & \multicolumn{4}{c}{ Initial Runoff Duration (min) } \\
\cline { 2 - 5 } & Type I & Type II & Type III & Type IV \\
\hline 1 & 47 & 46 & 38 & 36 \\
3 & 50 & 50 & 41 & 40 \\
7 & 51 & 49 & 43 & 42 \\
\hline
\end{tabular}

When the structure forms of the base were the same, the initial runoff time of type III and IV permeable pavements was 7 to 10 min earlier than that of type I and II permeable pavements. This indicated that the material of the leveling layer had a greater influence on the initial runoff time. When using medium sand, the porosity of the leveling layer was smaller, which reduced the infiltration capacity of the permeable pavement, and the runoff started earlier. In the case of the same material being used in the leveling layer, the runoff time of type II and IV permeable pavements was similar to that of type I and III 
permeable pavements (difference was within 1-2 min). This showed that under different rainfall intervals, the structure forms of the base had little effect on the initial runoff time.

\subsubsection{Runoff Coefficient}

The runoff coefficient of each permeable pavement under different rainfall intervals was shown in Figure 6. The shorter the rainfall interval, the greater the runoff coefficient. When the intermittent period was one, three, and seven days, the maximum runoff coefficients of each permeable pavement were $0.64,0.54$, and 0.52 , respectively. It can be seen that the maximum runoff coefficient was less affected by the rainfall intermittent period than by the rainfall intensity. The runoff coefficient of the same permeable pavement in the rainfall interval of three and seven days was similar, and the difference was larger than that of the rainfall interval of one day. This may be because when the intermittent period was short, the rainwater from the previous rainfall was retained in the permeable pavement structure, which led to a decrease in its infiltration capacity and an increase in the runoff coefficient $[29,31,32]$.

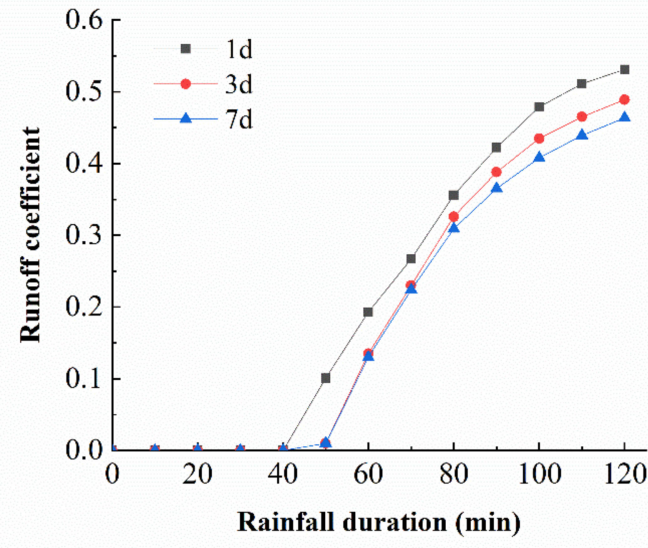

(a)

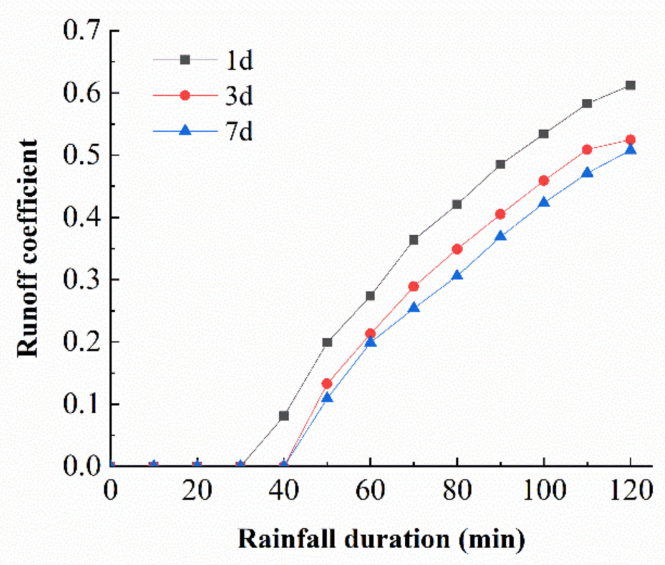

(c)

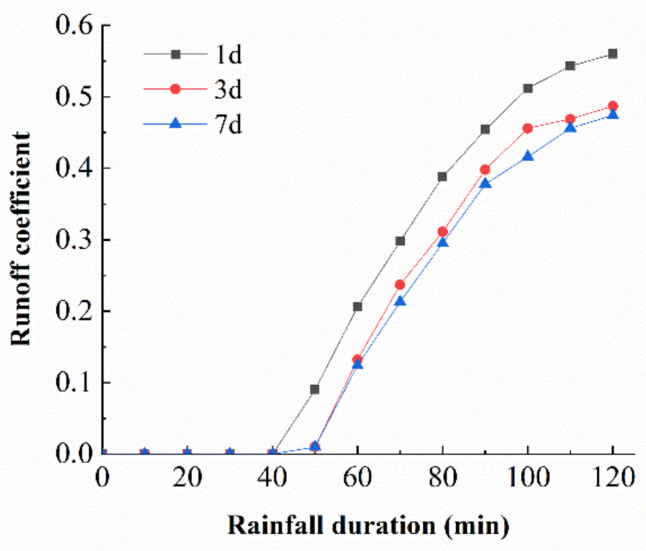

(b)

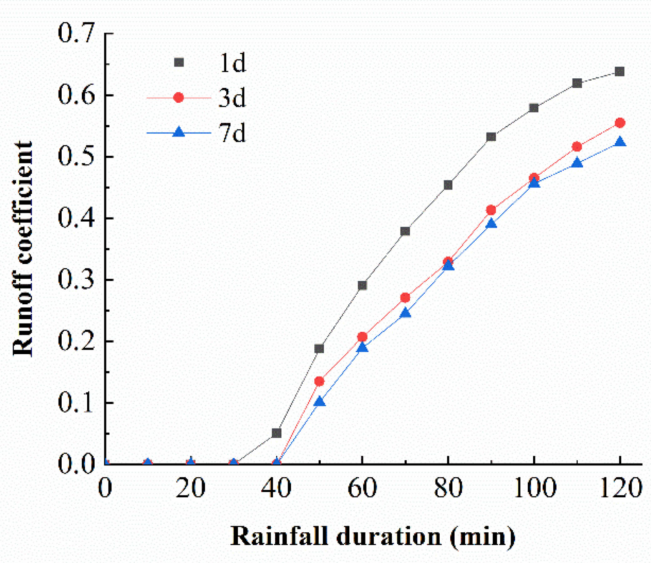

(d)

Figure 6. Runoff coefficient of each permeable pavement under different rainfall intervals; (a) type I; (b) type II; (c) type III; and (d) type IV.

When the material of the leveling layer was the same, the runoff coefficient of type I and type II permeable pavements was similar, as well as type III and type IV, indicating that the structure forms of the base had little effect on the runoff coefficient. The results revealed that when the structure forms of the base were the same, the runoff coefficient of type III and type IV permeable pavement with a medium sand screed were significantly higher 
than those of type I and type II permeable pavement with a screed layer of natural sand and gravel. Among them, when the rainfall interval was one day, the average maximum runoff coefficient of type III and type IV permeable pavements was 0.63 , which was $14.6 \%$ higher than that of type I and type II.

\subsubsection{Runoff Control Rate}

The runoff generation and cumulative infiltration of each prefabricated permeable pavement under different rainfall intervals are shown in Figure 7, and the runoff control rate was shown in Table 5. With the extension of the rainfall interval, the runoff generation of each pavement decreased, and the cumulative infiltration increased, so the runoff control rate increased. When the rainfall interval was one day, the runoff control rate of the permeable pavement was $36.2-46.9 \%$, with an average of $41.5 \%$. The maximum runoff control rate was obtained in type I permeable pavement when the rainfall interval was seven days, which was $53.6 \%$. When the rain interval was shortened from three days to one day, the runoff generation increased significantly $(10.6-20 \mathrm{~mm})$. The possible reason could be that when the intermittent period was short, rainwater from the previous rainfall was retained in the pavement, and the initial moisture content was relatively high. The results from previous studies revealed that in the case of high initial water content in the permeable pavement, the storage space of the pavement layer was occupied by the rain that occurred in the previous period and the runoff generation was high, which is consistent with this experiment [19,33-37]. Similarly, many researchers also noted that the permeable pavements are highly effective in mitigating runoff from smaller, less intense rainfall events separated by antecedent dry period $[8,38,39]$.

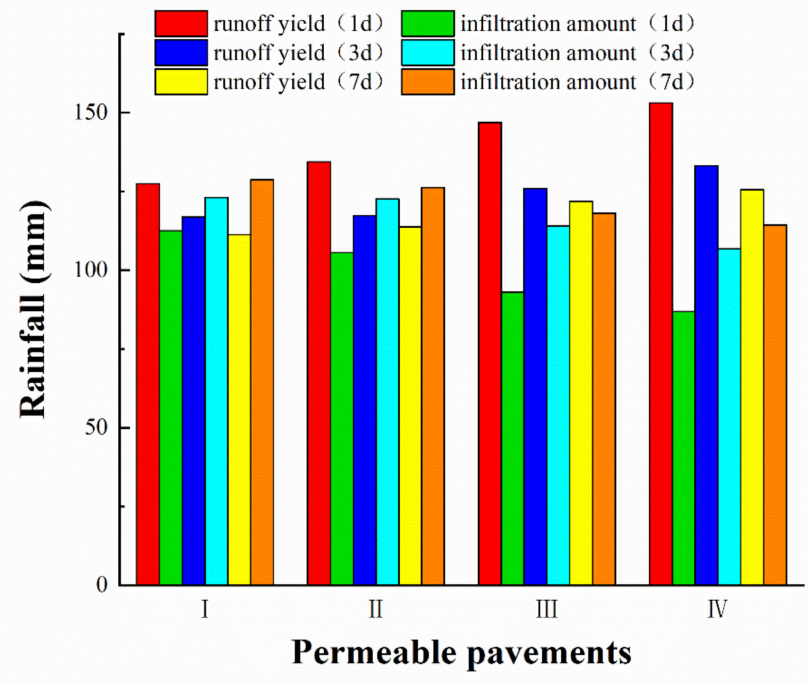

Figure 7. Yield and infiltration amount of each permeable pavement under different rainfall intervals.

Table 5. Initial runoff time of each permeable pavement under different rainfall intervals.

\begin{tabular}{ccccc}
\hline \multirow{2}{*}{$\begin{array}{c}\text { Rainfall Interval } \\
\text { (d) }\end{array}$} & \multicolumn{4}{c}{ Runoff Control Rate (\%) } \\
\cline { 2 - 5 } & Type I & Type II & Type III & Type IV \\
\hline 1 & 46.9 & 44.0 & 38.8 & 36.2 \\
3 & 51.3 & 51.1 & 47.5 & 44.5 \\
7 & 53.6 & 52.6 & 49.2 & 47.7 \\
\hline
\end{tabular}

Under similar rainfall intervals, the runoff control rate of type I and type II permeable pavement was similar (within 3\%), and so was that of type III and type IV pavement, indicating that the structure forms of the base had little effect on the runoff control rate. It is evident that when the rainfall interval was one day, the difference in the runoff control 
rate of the permeable pavement of type I and type III, type II and type IV was $8.1 \%$ and $7.8 \%$, respectively. It showed that when the rainfall interval was short, the material of the leveling layer had a greater influence on the runoff control rate. This trend also occurred because the previous rainwater was retained in the pavement, and the infiltration capacity was reduced, which shows consistency with other research findings $[40,41]$. Compared with natural sand and gravel, the medium sand had a stronger water holding capacity, and it took longer to empty the rainwater [11,41]. Future research work could consider various other factors, such as land use patterns, soil type, topography, runoff quality and quantity, and contamination in nearby water resources, along with pavement design and possible filler materials [5,11,12,29,38-42]. The findings of the current study provide an opportunity for the successful implementation and beneficial use of permeable pavements based on the local urban environment and land use pattern, and climatic, geological, and hydrologic conditions.

\section{Conclusions}

The current findings revealed that each prefabricated permeable pavement had good runoff control performance. Results showed that within $2 \mathrm{~mm} / \mathrm{min}$ rainfall intensity and the initial runoff time was at least $42 \mathrm{~min}$, the maximum runoff coefficient was 0.52 and the minimum runoff control rate was $47.7 \%$. In case when the rainfall interval was one day, the initial runoff time of each permeable pavement was at least $36 \mathrm{~min}$ and the maximum runoff coefficient was 0.64 and the average runoff control rate was $41.5 \%$. The leveling layer material had a greater impact on the hydrological effect of the permeable pavement. When the base was assembled in the same form, the permeable pavement with a medium sand leveling layer generated runoff around 4.5-10 min in advance, and the runoff control rate could be reduced by $4.4-8.1 \%$. In shorter rainfall intervals, the leveling layer material had a greater influence on the runoff coefficient. Compared with the natural sand and gravel, when the medium sand was used, the maximum runoff coefficient of the permeable pavement increased by about $14.6 \%$. The assembly form of the precast concrete had little influence on the hydrological effect of the permeable pavement. Results also reveal that in similar material for the leveling layer, the permeable pavement with the b-type base was 1-2 min earlier than the pavement with a-type base, and there was no significant difference in the runoff coefficient and the runoff control rate. Under different rainfall intensities and rainfall intervals, the runoff control performance of type I permeable pavement is the best. According to the three parameters under different rainfall intensities and rainfall intervals, the runoff control performance of type I permeable pavement was the best. The current findings also reveal the potential use of permeable pavements in filled applications in the investigated urban areas.

Author Contributions: Conceptualization, K.D., W.L., X.S., D.F., C.Z. and R.P.S.; methodology, K.D., W.L., X.S., D.F. and R.P.S.; validation, D.F. and R.P.S.; formal analysis, K.D., W.L. and X.S.; investigation, K.D., W.L., X.S., D.F. and R.P.S.; resources, D.F.; data curation, K.D., W.L., X.S. and R.P.S.; writingoriginal draft preparation, K.D., W.L. and R.P.S.; writing-review and editing, D.F., C.Z. and R.P.S.; visualization, K.D., D.F. and R.P.S.; supervision, D.F., C.Z. and R.P.S.; project administration, D.F. All authors have read and agreed to the published version of the manuscript.

Funding: This research was supported by National Natural Science Foundation of China (No. 51950410589).

Informed Consent Statement: Not applicable.

Data Availability Statement: The data presented in this study are available on request from authors.

Acknowledgments: Authors would like to thank Southeast University and Jiangsu Sponge City Material and Performance Testing Engineering and Technology Research Center, Kunshan for providing necessary permissions and facilities for conducting this work. 
Conflicts of Interest: The authors declare no conflict of interest. The funders had no role in the design of the study; in the collection, analyses, or interpretation of data; in the writing of the manuscript, or in the decision to publish the results.

\section{References}

1. Hu, M.C.; Zhang, X.Q.; Siu, Y.L.; Li, Y.; Tanaka, K.; Yang, H.; Xu, Y.P. Flood Mitigation by Permeable Pavements in Chinese Sponge City Construction. Water 2018, 10, 172. [CrossRef]

2. Zhu, Z.; Chen, X. Evaluating the Effect of Low Impact Development Practices on Urban Flooding Under Different Rainfall Intensities. Water 2017, 9, 548. [CrossRef]

3. Martins Vaz, I.C.; Ghisi, E.; Thives, L.P. Stormwater Harvested from Permeable Pavements as a Means to Save Potable Water in Buildings. Water 2021, 13, 1896. [CrossRef]

4. Kumar, A.; Taxak, A.K.; Mishra, S.; Pandey, R. Long Term Trend Analysis and Suitability of Water Quality of Himalayan Hills of Uttrakhand, India. Environ. Technol. Innov. 2021, 22, 101405. [CrossRef]

5. Collins, A.K.; Hunt, W.F.; Hathaway, J.M. Hydrologic Comparison of Four Types of Permeable Pavement and Standard Asphalt in Eastern North Carolina. J. Hydrol. Eng. 2008, 13, 1146-1157. [CrossRef]

6. Yang, F.K.; Fu, D.F.; Liu, S.; Zevenbergen, C.; Singh, R.P. Hydrologic and Pollutant Removal Performance of Media Layers in Bioretention. Water 2020, 12, 921. [CrossRef]

7. Ding, N. Study on Parking Standard for Construction Projects in Harbin. Master's Thesis, Chang'an University, Xi'an, China, May 2019.

8. Nguyen, T.H.; Ahn, J. Numerical Study on the Hydrologic Characteristic of Permeable Friction Course Pavement. Water 2021, 13, 843. [CrossRef]

9. Kumar, K.; Kozak, J.; Hundal, L.; Cox, A.; Zhang, H.; Granato, T. In-situ Infiltration Performance of Different Permeable Pavements in a Employee Used Parking Lot-A Four-year Study. J. Environ. Manag. 2016, 167, 8-14. [CrossRef]

10. Pratt, C.J.; Mantle, J.D.G.; Schofield, P.A. Urban Stormwater Reduction and Quality Improvement through the Use of Permeable Pavements. Water Sci. Technol. 1989, 21, 769-778. [CrossRef]

11. Hunt, B.; Stevens, S.; Mayes, D. Permeable Pavements Use and Research at Two Sites in Eastern North Carolina. In Proceedings of the 9th International Conference on Urban Drainage, Global Solutions for Urban Drainage, ASCE, Portland, OR, USA, 8-13 September 2002.

12. Brattebo, B.O.; Booth, D.B. Long-term Stormwater Quantity and Quality Performance of Permeable Pavement Systems. Water Res. 2003, 37, 4369-4376. [CrossRef]

13. Bean, E.Z.; Hunt, W.F.; Bidelspach, D.A. Field Survey of Permeable Pavement Surface Infiltration Rates. J. Irrig. Drain. Eng. 2007, 133, 247-255. [CrossRef]

14. Wang, J.L.; Wang, X.M.; Zhang, A.; Zhang, Y. Review on Permeable Pavement Systems Based on the Concept of "Sponge City" Runoff Management Performances of Permeable Pavements: A Review. Environ. Eng. 2015, 33, 1-4. (In Chinese)

15. Wei, S.; Wu, L.P.; Li, J. Discussion on the Application of Water Permeable Brick in the Construction of Sponge City. China Water Wastewater 2017, 33, 1-5.

16. Li, Z.Z.; Dong, M.J.; Wong, T.; Wang, J.B.; Kumar, A.J.; Singh, R.P. Objectives and Indexes for Implementation of Sponge Cities-A Case Study of Changzhou City, China. Water 2019, 11, 81. [CrossRef]

17. Li, M.Y.; Zhang, S.H.; Wang, Y.J.; Wang, Y.Q. Runoff Management Performances of Permeable Pavements: A Review. Environ. Sci. Technol. 2018, 41, 105-112.

18. Cheng, Y.-Y.; Lo, S.-L.; Ho, C.-C.; Lin, J.-Y.; Yu, S.L. Field Testing of Porous Pavement Performance on Runoff and Temperature Control in Taipei City. Water 2019, 11, 2635. [CrossRef]

19. Park, J.; Park, J.; Cheon, J.; Lee, J.; Shin, H. Analysis of Infiltrating Water Characteristics of Permeable Pavements in a Parking Lot at Full Scale. Water 2020, 12, 2081. [CrossRef]

20. Ghisi, E.; Belotto, T.; Thives, L.P. The Use of Permeable Interlocking Concrete Pavement to Filter Stormwater for Non-Potable Uses in Buildings. Water 2020, 12, 2045. [CrossRef]

21. Zhu, X.J.; Liu, J.; Wu, W. Application of Slotted Permeable Pavement in the Construction of Sponge City: Taking Zhenjiang as an Example. China Water Wastewater 2017, 33, 1-4.

22. Li, J.; Zhang, Y.; Liu, G.; Peng, X.H. Preparation and Performance Evaluation of an Innovative Pervious Concrete Pavement. Constr. Build. Mater. 2017, 138, 479-485. [CrossRef]

23. Braswell, A.S.; Winston, R.J.; Hunt, W.F. Hydrologic and Water Quality Performance of Permeable Pavement with Internal Water Storage over a Clay Soil in Durham, North Carolina. J. Environ. Manag. 2018, 224, 277-287. [CrossRef]

24. Lin, W.; Kim, I.T.; Kim, H.; Cho, Y.H. Water Runoff Characteristics in Porous Block Pavements Using an Accelerated Pavement Tester. J. Hydrol. Eng. 2014, 19, 04014012. [CrossRef]

25. Walter, E.; Sieglen, J.; Langsdorff, H.V. Interlocking Concrete Block Pavements at Howland Hook Marine Terminal. In Proceedings of the Ports Conference 2004, Houston, TX, USA, 23-26 May 2004; pp. 1-10.

26. Yang, Y.J. An Assembled Permeable Sidewalk Base Block. Patent No. 201721177033.9, 13 September 2017.

27. Yang, H.; Chen, H.M.; Huang, X. An Ecological Permeable Pavement. Patent No. 201910336928.X, 23 April 2019. 
28. Bateni, N.; Lai, S.H.; Putuhena, F.J.; Mah, D.Y.S.; Mannan, M.A.; Chin, R.J. Hydrological Performances on the Modified Permeable Pavement with Precast Hollow Cylinder Micro detention Pond Structure. KSCE J. Civ. Eng. 2019, 23, 3951-3960. [CrossRef]

29. Liu, W.; Feng, Q.; Chen, W.; Ravinesh, C.D. Stormwater Runoff and Pollution Retention Performances of Permeable Pavements and the Effects of Structural Factors. Environ. Sci. Pollut. Res. 2020, 27, 30831-30843. [CrossRef]

30. Zhang, S.H.; Chen, J.G.; Zhao, F.; Hou, L.Z. Experimental Study on Pavement Structure of Pervious Bricks Based on Infiltration and Runoff Generation Analysis. Adv. Sci. Technol. Water Resour. 2011, 31, 39-42.

31. Alyaseri, I.; Zhou, J.P. Stormwater Volume Reduction in Combined Sewer Using Permeable Pavement: City of St. Louis. J. Environ. Eng. 2016, 142, 04016002. [CrossRef]

32. USEPA (United States Environmental Protection Agency). Porous Asphalt Pavements; United States Environmental Protection Agency: Washington, WA, USA, 2009.

33. Zhao, F.; Chen, J.G.; Zhang, S.H.; Su, D.B.; Gong, Y.A. Study of Rainfall-Runoff Model at Permeable Pavement. Water Wastewater Eng. 2010, 46, 154-159.

34. Shafique, M.; Kim, R.; Kyung-Ho, K. Rainfall Runoff Mitigation by Retrofitted Permeable Pavements in an Urban Area. Sustainability 2018, 10, 1231. [CrossRef]

35. Antunes, L.N.; Sydney, C.; Ghisi, E.; Phoenix, V.R.; Thives, L.P.; White, C.; Garcia, E.S.H. Reduction of Environmental Impacts Due to Using Permeable Pavements to Harvest Stormwater. Water 2020, 12, 2840. [CrossRef]

36. Alam, T.; Mahmoud, A.; Jones, K.D.; Bezares-Cruz, J.C. A Comparison of Three Types of Permeable Pavements for Urban Runoff Mitigation in the Semi-Arid South Texas, USA. Water 2019, 11, 1992. [CrossRef]

37. Li, H.Y.; Li, Z.F.; Zhang, X.R.; Li, Z.R.; Liu, D.Q.; Li, T.H.; Zhang, Z.Y. The Effect of Different Surface Materials on Runoff Quality in Permeable Pavements Systems. Environ. Sci. Pollut. Res. 2017, 24, 21103-21110. [CrossRef]

38. Tirpak, R.A.; Winston, R.J.; Simpson, I.M.; Dorsey, J.D.; Grimm, A.G.; Pieschek, R.L.; Petrovskis, E.A.; Carpenter, D.D. Hydrologic Impacts of Retrofitted Low Impact Development in a Commercial Parking Lot. J. Hydrol. 2021, 592, 125773. [CrossRef]

39. Daniel, J.; Nora, S.; Susanne, C.; Ignacio, A. Coupling GIS with Stormwater Modelling for the Location Prioritization and Hydrological Simulation of Permeable Pavements in Urban Catchments. Water 2016, 8, 451.

40. Tirpak, R.A.; Winston, R.J.; Feliciano, M.; Dorsey, J.D.; Epps, T.H. Impacts of Permeable Interlocking Concrete Pavement on the Runoff Hydrograph: Volume Reduction, Peak Flow Mitigation and Extension of Lag Times. Hydrol. Process 2021, 35, e14167. [CrossRef]

41. Kumar, A.; Pinto, M.C.; Candeias, C.; Dinis, P.A. Baseline Maps of Potentially Toxic Elements in the Soils of Garhwal Himalayas, India: Assessment of their Eco-environmental and Human Health Risks. Land Degrad. Dev. 2021, 9, 3984. [CrossRef]

42. Kumar, A.; Jigyasu, D.K.; Kumar, A.; Subrahmanyam, G.; Mondal, R.; Shabnam, A.A.; Cabral-Pinto, M.M.S.; Malyan, S.K.; Chaturvedi, A.K.; Gupta, D.K.; et al. Nickel in Terrestrial Biota: Comprehensive Review on Contamination, Toxicity, Tolerance and its Remediation Approaches. Chemosphere 2021, 10, 1016. [CrossRef] 